\title{
SEISMIC ANALYSIS OF A MEXICAN VIADUCT WITH NONLINEAR MODELING OF SOIL-STRUCTURE INTERACTION
}

\author{
Cláudia Coelho ${ }^{1}$, António Arêde ${ }^{2}$, Pedro Delgado ${ }^{3}$ and José Barbosa ${ }^{4}$ \\ ${ }^{1}$ Faculdade de Engenharia (FEUP) Universidade do Porto \\ R. Dr. Roberto Frias, s/n 4200-465 Porto, Portugal \\ csmpc@,outlook.com
}
${ }^{2}$ CONSTRUCT-LESE, Faculdade de Engenharia (FEUP) Universidade do Porto
R. Dr. Roberto Frias, s/n 4200-465 Porto, Portugal aarede@fe.up.pt
${ }^{3}$ Instituto Politécnico de Viana do Castelo / CONSTRUCT-LESE
Apartado 574, 4901-908 Viana do Castelo, Portugal
pdelgado@estg.ipvc.pt
${ }^{4}$ Gabinete de Estruturas e Geotécnia
Rua Justino Teixeira, Esc A-307 4300-273 Porto, Portugal
jbarbosa@geg-engineering.com

\begin{abstract}
Every day the need to understand earthquakes and how that phenomenon affects construction grows, to make it possible to prevent and minimize inherent risks to their relation. That need increases when projects are located in regions with large seismicity. Therefore, the present paper, which was developed in partnership with GEG - Gabinete de Estruturas e Geotecnia, has, as a final goal, to study and compare the variety of calculation methods available on Eurocode 8 to design and evaluate earthquake resistant structures, using a real case study.

The methods approached are linear dynamic analysis, also known as spectral analysis, nonlinear static analysis, also recognized as pushover analysis, and non-linear dynamic analysis, well-known as time-history analysis.

Simultaneously to the seismic analyses, it is developed a detailed study of the parameters that affect the damping of soil-structure interaction.
\end{abstract}

Keywords: Seismic design, Bridges, Nonlinear models of soil, Pushover analysis, Non-linear dynamic analysis 


\section{INTRODUCTION}

Given the significance of bridges and viaducts in today's society, particularly in the socioeconomic sector, it becomes increasingly important to deepen the knowledge on the typical behaviour of special structures when exposed to seismic actions. Only then we will be able to fully understand and optimise seismic analysis methods and consequently the structure's design, guaranteeing a better quality and increasing its safety.

Located near four tectonic plates, Mexico is one of the world's most seismically active regions. The historic earthquake of 1985 caused thousands of deaths and hundreds of buildings to collapse. This shows that, in areas with such intense seismic activity, it is extremely important to anticipate, in design stage, possible structural failure modes due to the dynamic loads during design stage, to make it possible to foresee and minimise potential damages caused by earthquakes. Following on this requirement, the current study's goal is to compare results from three frequently carried seismic analysis as stated in the relevant codes: Linear dynamic analysis, also known as spectral analysis; Non-linear static analysis or Pushover analysis; and Non-linear dynamic analysis, frequently known as time-history analysis. The results from the three methods will be presented for the critical sections of a viaduct in terms of stresses, deflections and ductility.

Further to the analyses, it is the final goal of this study to assess how carrying out a full non-linear dynamic analysis affects the seismic design of a structure, compared to the simplified spectral analysis most frequently used. Additionally, and to get more accurate results, the study comprises an analysis of the material hysteretic damping originated by the soil in contact with the foundations, where the soil is modelled by a multilinear model which is still little used. The approach will analyse the cyclic behaviour of the ground under seismic actions, the different parameters which influence this behaviour and how these parameters affect the hysteretic damping derived from the soil-structure interaction.

\section{CASE STUDY}

\subsection{Structural Solution}

The case study, located in Mexico is a regular viaduct with three continuous spans - a 24 meter long midspan and two 20 meter long endspans. The structure consists of 1.6 meter deep pre-stressed pre-fabricated AASHTO beams in the longitudinal direction, centred at 2.172 meters, making the total width of the deck 13.6 meters, as shown in figure 1. These main beams are monolithically connected to the piers through crosshead beams with an inverted $\mathrm{T}$ section, as per figure 2 . The deck slab is built of $7.5 \mathrm{~cm}$ thick pre-fabricated concrete paving flags which span between the longitudinal beams and screeded over, making the deck $20 \mathrm{~cm}$ deep. 

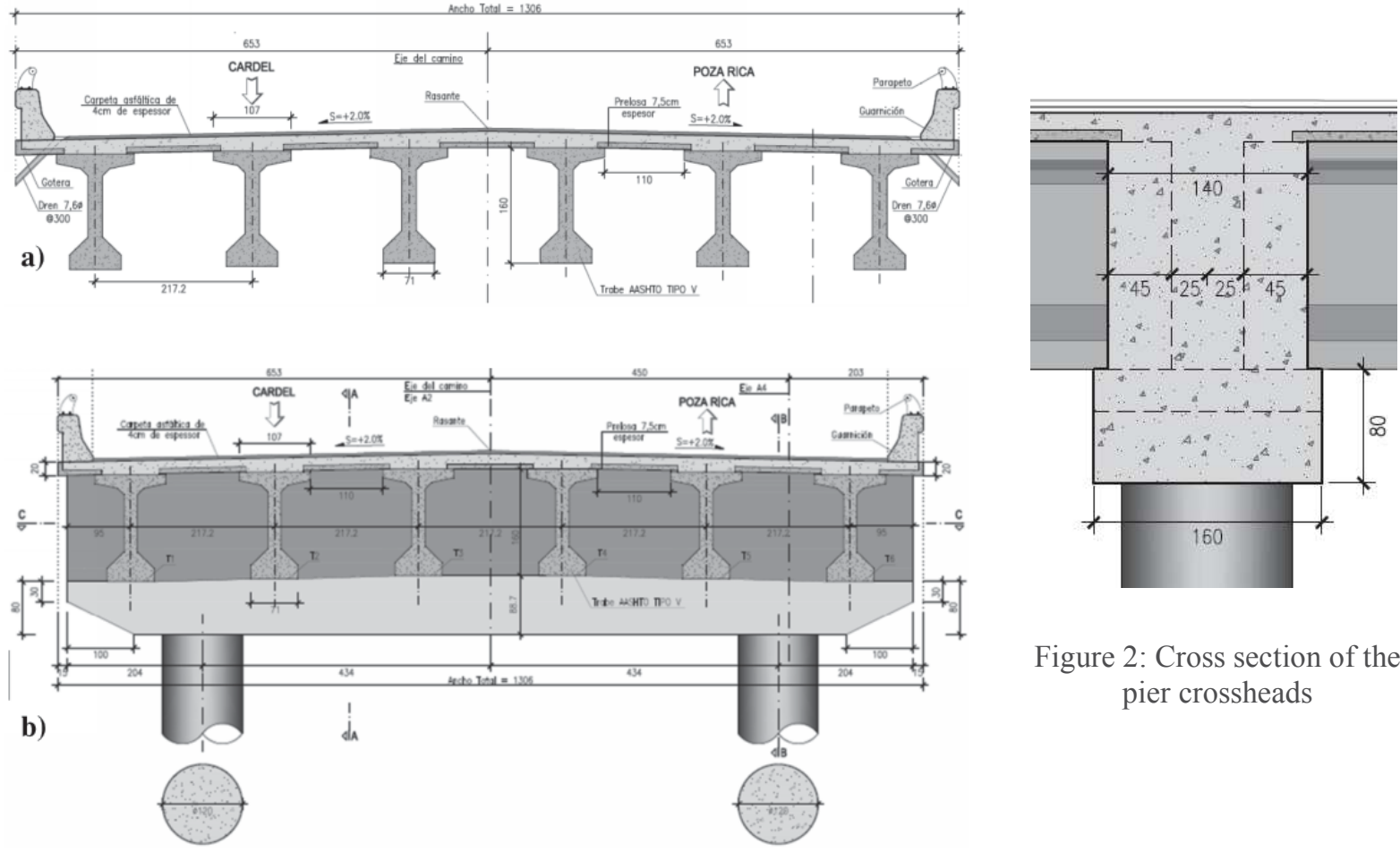

Figure 2: Cross section of the pier crossheads

Figure 1: Cross section of the deck at: a) midspan b) through pier crossheads

The 1.2 meter of diameter circular piers have a variable effective length between 5.4 and 6.3 meters above ground, and extend to 15 meters below ground, acting as piles as well. These elements include, through its full length, 3 different sections with variable reinforcement, as per figure 3. The first section, shown in figure $3 \mathrm{a}$, shows the section above ground. The second section, shown in figure $3 \mathrm{~b}$, shows the reinforcement between ground level and a depth of 5 meter into the pile length. At last, the section presented in figure $3 \mathrm{c}$ extends to the end of piles.

The supports on the abutments consists of neoprene and Teflon, allowing the deck to movement in the longitudinal direction but not on the transversal one. The supports also allow for rotation around the transversal axis. The U-Type abutments, built in reinforced concrete, sit on a $1.9 \mathrm{~m}$ wide x $1.0 \mathrm{~m}$ deep beam which bears on circular piles of 1.2 meters of diameter. These piles extend, similarly to the intermediate ones, to 15 meters below the ground level and the reinforcement varies creating four different sections, as shown in figure 4 . The sections presented in figures $4 \mathrm{a}, 4 \mathrm{~b}$ and $4 \mathrm{c}$ can be found through $2+2+4$ meters (from ground level to a depth of 8 meters) and the section shown in $4 \mathrm{~d}$ will follow to the end of the pile.

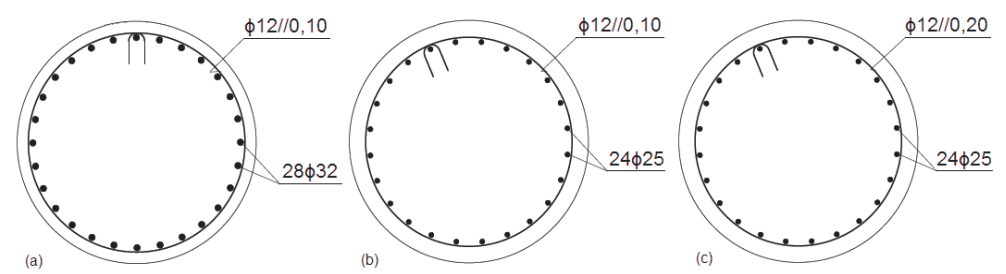

Figure 3: Cross section of the intermediate piers/piles a) from the soffit of the deck to ground level; b) between ground level and 5 meters below ground; c) from 5 meters below ground to bottom of pile 


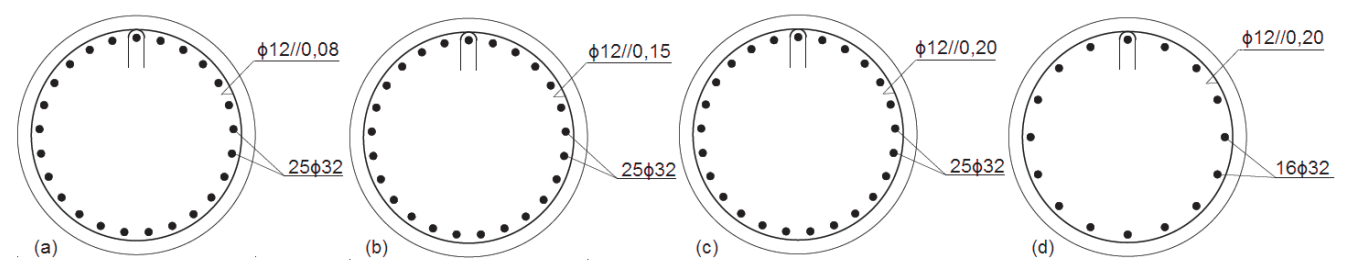

Figure 4: Cross section of the abutment piles: a) first 2 meters of depth; b) between 2 and 4 meters below ground; c) from 4 to 8 meters below ground; d) for the remainder 7 meters to bottom of pile

\subsection{Geotechnical scenario}

The geotechnical scenario in the area of the viaduct is composed of four different types of soil. The first layer consists of vegetable mould, characterised by a dark soil rich in organic material. The second layer is an alluvial soil which includes coarse sand with alternate layers of silty sand. The third layer, where the piles bear, is composed of medium/coarse gravel on a sandy-clay matrix. At last, 26 meters below ground level, it is found a soft rock made of sandstones and siltstones.

\section{MODEL}

\subsection{Grid model in SeismoStruct}

The viaduct has been modelled as a grid using the FEM software SeismoStruct. The grid model is based on bar elements that, as a group, simulate the behaviour of the viaduct deck. For the effect, the modelled deck comprises six groups of longitudinal elements with an equivalent rectangular section with the same inertial characteristics as the pre-fabricated beams. This has been achieved by manipulating the elastic modulus of the concrete, using a value of $22 \mathrm{GPa}$, so that the group of bars simulates the behaviour of the real full section of the deck. In the transversal direction, the model comprises 33 bar elements, which include: 29 bars with a $2 \times 0.2 \mathrm{~m}^{2}$ section, which mimic the bending stiffness of the deck in the relevant direction; 2 bars which simulate the pier crossheads; and 2 elements which represent the beams which connect the U-Type abutments to the piles supporting them. The eccentricity between different element's gravity centres has been taken into account by offsetting the relevant bars. The intermediate piers, as well as the piles supporting the abutments, are modelled with continuous bars with a circular section of $1.2 \mathrm{~m}$ of diameter.

\subsection{Nonlinear modelling of the soil}

The plasticity of soils, characterised by its stress (p) - deformation (y) curves, is a widely recognised theme, just as the typical hysteretic curves for soils which are based on the same concepts and are represented in figure 5. However, curves such as the one shown below don't adequately characterise the behaviour of non-grained soils. As suggested by W. Cofer and S. Modak [1], the lack of capacity of some types of soil to retake its original position once deformed, and how that influences the non-linear behaviour of cohesive soils, are immensely important topics which lack study.

If a cohesive soil is imposed a certain displacement, it does not have the elastic capacity to retrieve its original position, creating a gap in which the structural element can move with little resistance. The phenomenon, represented in figure 6a, originates hysteretic curves such as the one shown in figure $6 \mathrm{~b}$ and highly affects the hysteretic damping generated by the soilstructure interaction in the event of an earthquake. Furthermore, if a soil is highly cohesive, 
meaning its capacity of returning to its original position is approximately null, its characteristic hysteretic curve will resemble the one presented in figure 7.

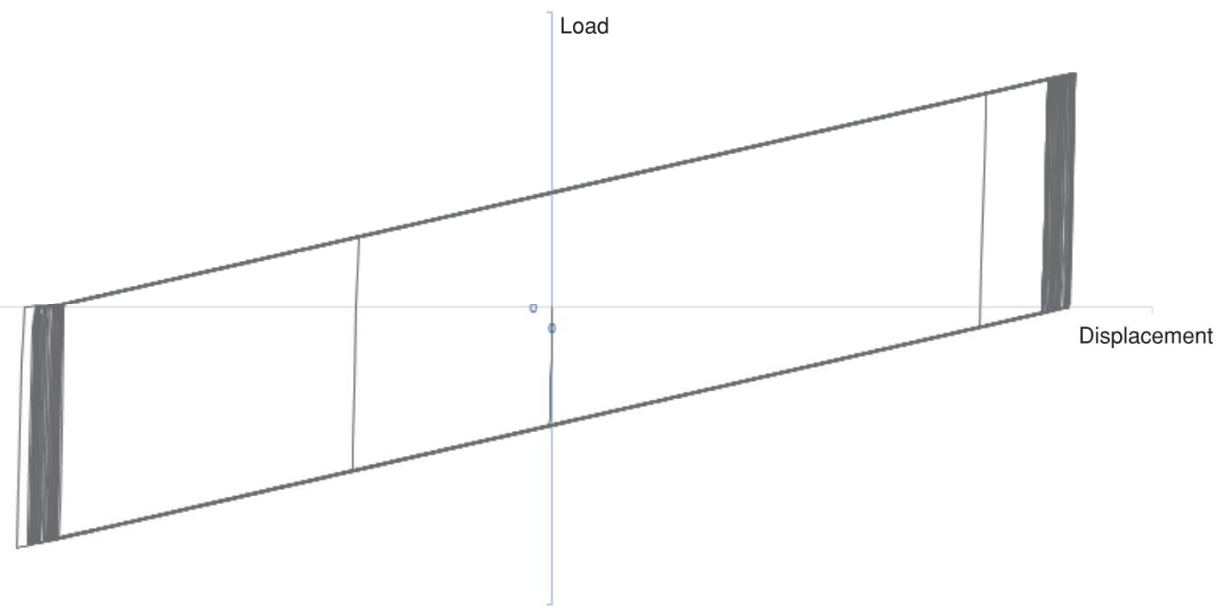

Figure 5: Typical hysteretic curve of a non-cohesive soil

(a)

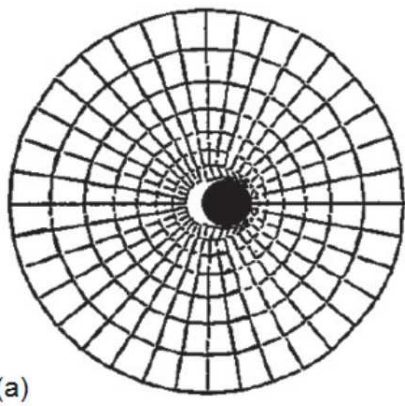

(b)

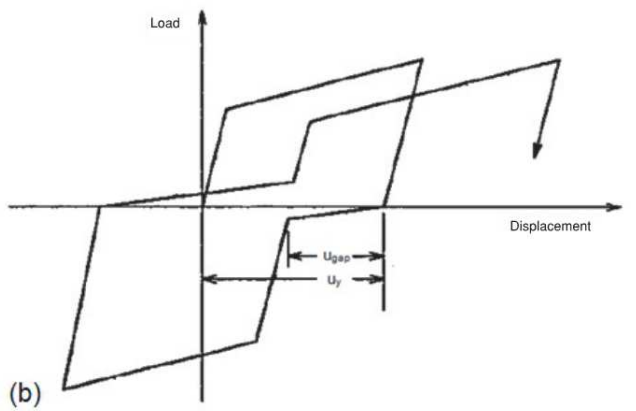

Figure 6: a) Gap created by plastic deformation of the soil ${ }^{[1]}$; b) Typical hysteretic curve of a medium-cohesive soil, taking into account the partial formation of a gap ${ }^{[1]}$

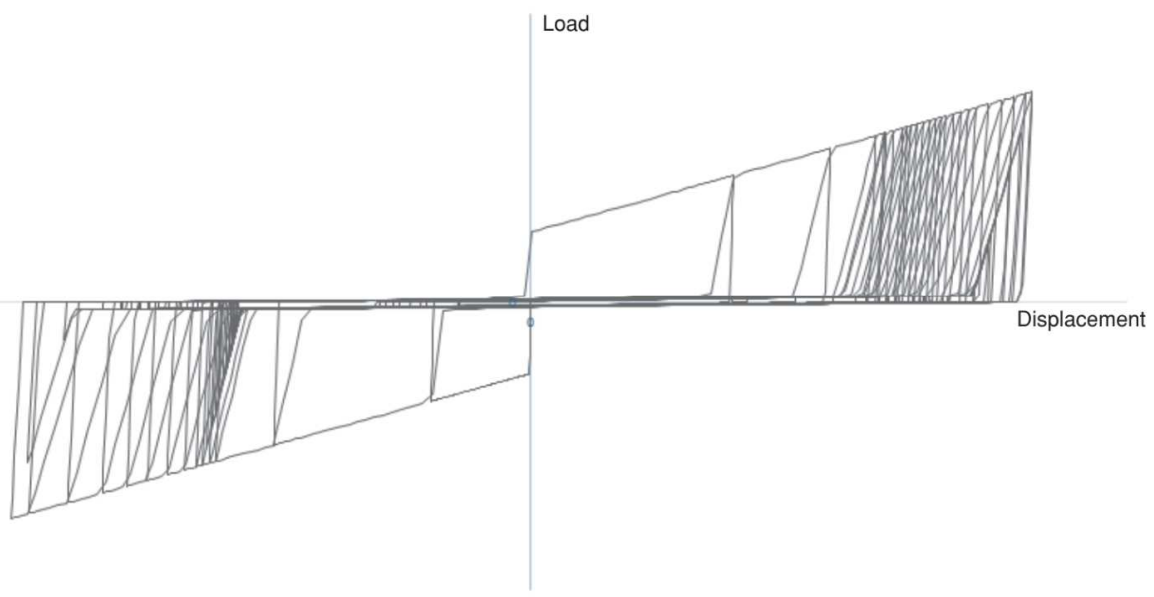

Figure 7: Typical hysteretic curve of a highly cohesive soil, accounting for the creation of the full gap

To better quantify the effective damping prior in the case study, it is decisive to understand which hysteretic behaviour best characterises our soil. Therefore, it is crucial to deeply understand how this gap affects the hysteretic damping factor. Additionally, not knowing the post- 
yielding stiffness of the soil, and that being one of the main influences in the hysteretic damping originated by the soil, it becomes fundamental to further investigate the parameter prior to adopting a value in the seismic analysis. To understand both these variables, a parametric study of a non-linear model of soil was carried out, focusing on these two parameters - the stiffness of the gap and the post-yielding stiffness of the soil, henceforth HS and \%EI3P, respectively.

\subsubsection{Bases for the study}

A displacement rule has been obtained off the response of a single degree of freedom damped system in resonance, using the behaviour factor adopted in the project and the yielding displacement of the ground surrounding the viaduct foundations, and applied as a dynamic load to a simplified model.

The simplified model consists only of one bar element with negligible stiffness, fixed on its base and propped at the top by a spring support. The stiffness of the spring support, which represents the soil, has been determined from the p-y curve presented below, in figure 8 .

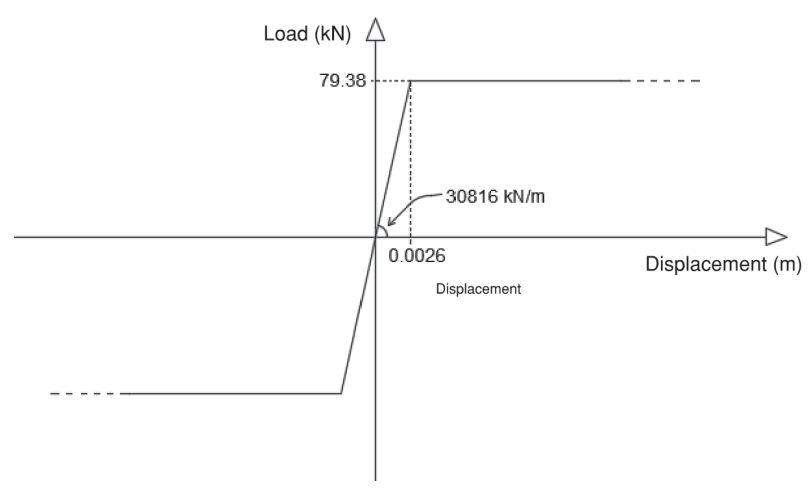

Figure 8: P-y curve adopted to characterize the spring support in the simplified

The parameter HS is presented as a percentage of the yielding load of the soil and \%EI3P is taken to be a fraction of the initial stiffness of the soil and this study has been carried out by varying each of the parameters separately. In order to evaluate the influence of HS, the value of $\% \mathrm{EI} 3 \mathrm{P}$ has been fixed at $0.1 \%$ as $\% \mathrm{EI} 3 \mathrm{P}$ was set to $10 \%, 20 \%, 30 \%$ and $50 \%$. On the other hand, to assess how \%EI3P impacts the damping, the parameter has been set to the same values of $10 \%, 20 \%, 30 \%$ and $50 \%$ while fixing HS at $0.1 \%$. 


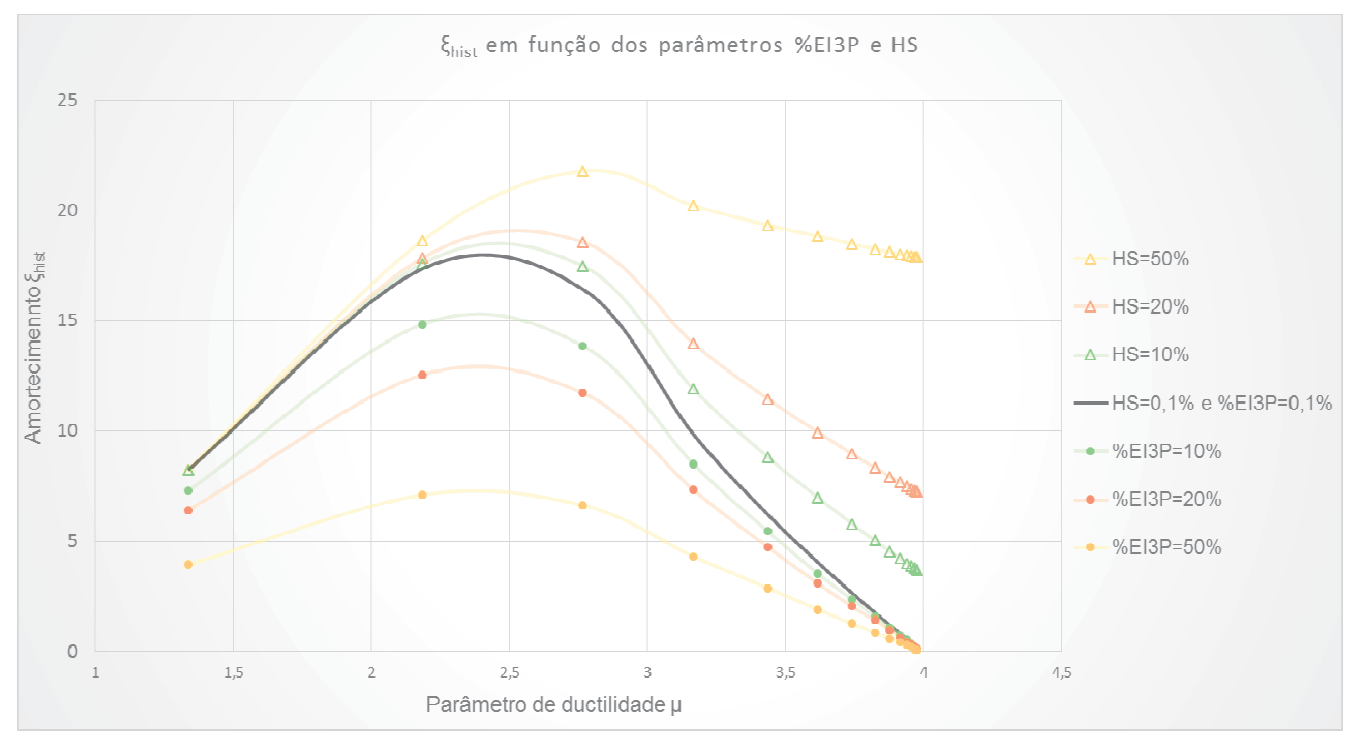

Figure 9: hist (hysteretic damping) - $\mu$ (ductility parameter) curves obtained in the study of the parameters HS and $\% \mathrm{EI} 3 \mathrm{P}$

\subsubsection{Conclusions}

The results for each of the combinations mentioned above are characterised by $\xi$ hist (hysteretic damping) - $\mu$ (ductility parameter) curves, which are presented in figure 9.

As expected, the higher the stiffness of the gap, the higher the damping derived from the soil as there is more energy being dissipated per cycle. However, it is noted that the fluctuation is negligible in the first few energy dissipation cycles, which are the ones that more accurately describe the global damping of the soils. This is observable for every combination of values except where HS is fixed at 50 . We can then conclude that, for realistic values of the gap stiffness, the damping will be maintained in the same range.

Regarding the post-yielding stiffness, it is observed that, as this parameter increases in value, the hysteretic damping originated from the soil decreases substantially. This result is conceivable as, the higher the post-yielding stiffness of the soil at a certain node, the easier will be for the soil at that node to become plastic, accommodating then higher loads for a limited displacement.

Taking into account the results described above and having as a base the study carried out by W. Cofer \& S. Modal [1], it has been adopted a value of $20 \%$ for the stiffness of the gap and $10 \%$ for the post-yielding stiffness in the following seismic analyses.

\section{SEISMIC ANALYSES}

\subsection{Bases for the different approaches}

\subsubsection{Linear dynamic analysis with response spectrum}

The first step to carry the spectral analysis is to obtain, as per the Mexican regulations (SCT standard [2]), the elastic response spectrum adequate to the location of the viaduct, taking into account its importance class and ground type. The viaduct in study is located in Seismic Zone B of Mexico and it is a Class A structure. The soil is Type II ground. Therefore, following section 4 of the SCT Standard, the relevant response spectrum applicable to this seismic analysis is the one represented in figure 10. 


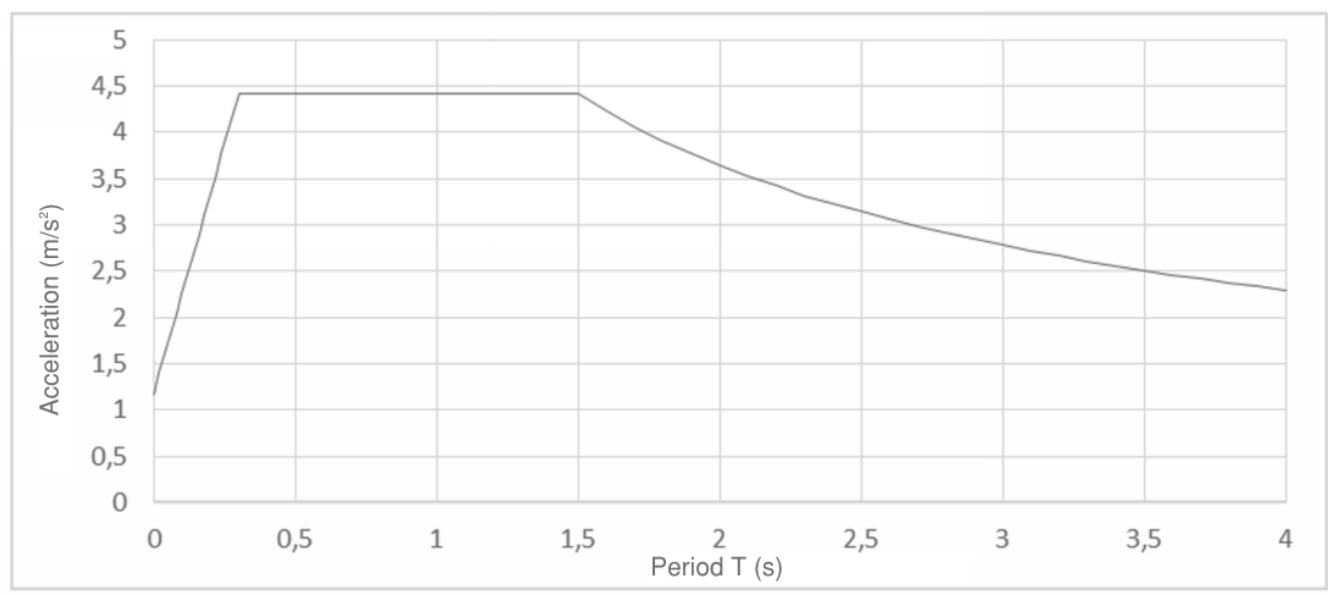

Figure 10: Response spectrum as per SCT standard

The second step on the spectral analysis is to determine which value of behaviour factor Q is adequate to the case study. The response spectrum above will then be affected by the behaviour factor in order to account for the non-linearity of the material. The characteristics of the viaduct indicate that a value of $\mathrm{Q}=4$ is adequate.

The analysis was carried out using safety factors as per the SCT standard and applying seismic loads in the two main directions, considering one of the directions affected by $100 \%$ of the seismic action and its orthogonal direction to be affected by $30 \%$ of it.

\subsubsection{Non-linear static analysis - Pushover analysis}

The pushover analysis consists of applying load increments to the structure and tracking its displacement for each of the increments - or vice-versa - creating the capacity curves of the structure, which relate the total base shear and the displacement of one particular control node. The analysis allows to understand if, for the design load, the structure will behave as envisioned in terms of stresses, ductility and formation of plastic hinges.

The analysis has been carried out in two main directions, for each applying $100 \%$ of the load in the direction under investigation and 30\% to its orthogonal. Note that, for each situation, several results combinations have been analysed, taking different control nodes, however, in this documents we will only present the results based on the displacement at the top of one of the piers, for each of the main directions.

It is important to note that the non-linear static analysis carried in this study is limited to evaluating the structure's monotonic response curve in order to compare it with the cyclic response, and the target displacement compatible with the seismic response spectrum is not quantified.

In order to accurately compare the results from the pushover analysis with the ones obtained through the spectral analysis, both have to be carried out with the same vertical loads applied the structure, comprising both the self-weight and superimposed dead loads (SDL) affected by a safety factor of 1.3 , as per Mexican Standards. The vertical loads are described in table 1 . 


\begin{tabular}{ccc}
\hline & \multicolumn{2}{c}{$\begin{array}{c}\text { AASHTO beams }+ \text { Slab }+ \\
\text { Safety barrier }\end{array}$} \\
\cline { 2 - 3 } Self-weight & Pier crossheads & 10111.6 \\
\cline { 2 - 3 } & Piers/Piles & 2722.67 \\
\hline Superimposed Dead Load (SDL) & 2202.78 \\
\hline
\end{tabular}

Table 1: Vertical loads in the structure $(\mathrm{kN})$

\subsubsection{Non-linear dynamic analysis - Time-history analysis}

The non-linear dynamic analysis, or time-history analysis, is a 'step-by-step' procedure and it is considered to be the most accurate seismic analysis as it does not include any simplifications or assumptions, taking into account the real non-linear behaviour of materials, and allowing for the damage to the structure through the analysis and its resulting mass changes. For this reason, further to determine stresses and displacements in structural elements due to a seismic action, the analysis also allows us to locate ductile areas of the structure and evaluate the structural damage due to a seismic occurrence.

Eurocode 8 provides guidance for the time-history analysis and declares that the seismic loads to be applied to the structure should be in the form of accelerograms, meaning timedependent ground accelerations, ideally derived from real seismic records. These records should relate to the relevant response spectrum in magnitude, distance from the source and travel path mechanisms. As per the Eurocode, the response of the structure shall be obtained averaging the response of analyses carried for at least seven pairs of accelerograms originated by seven different seismic records.

As, for the present study, there was no possibility to collect reliable seismic information from the area where the viaduct is located, the records used for the analyses have been gathered from different areas of the world where the ground is similar to the one found on the viaduct site. The seven accelerograms adopted have been selected from a database based on the similarity of the derived average spectrum with the elastic response spectrum, as per reference [2]. According to Eurocode 8, the spectral accelerations on the average spectrum obtained from the seismic records should not vary more $10 \%$ in a period range between $0.2 \mathrm{~T}$ and $2 \mathrm{~T}$, when compared to the standardised spectrum, where $\mathrm{T}$ is the fundamental period of the structure in the direction being analysed. Figure 11 shows the individual spectra derived from each seismic record, the average spectrum obtained from the seven pairs of individual spectra and the target spectrum (standardised), as well as $10 \%$ variation limits between $0.2 \mathrm{~T}$ and $2 \mathrm{~T}$. 


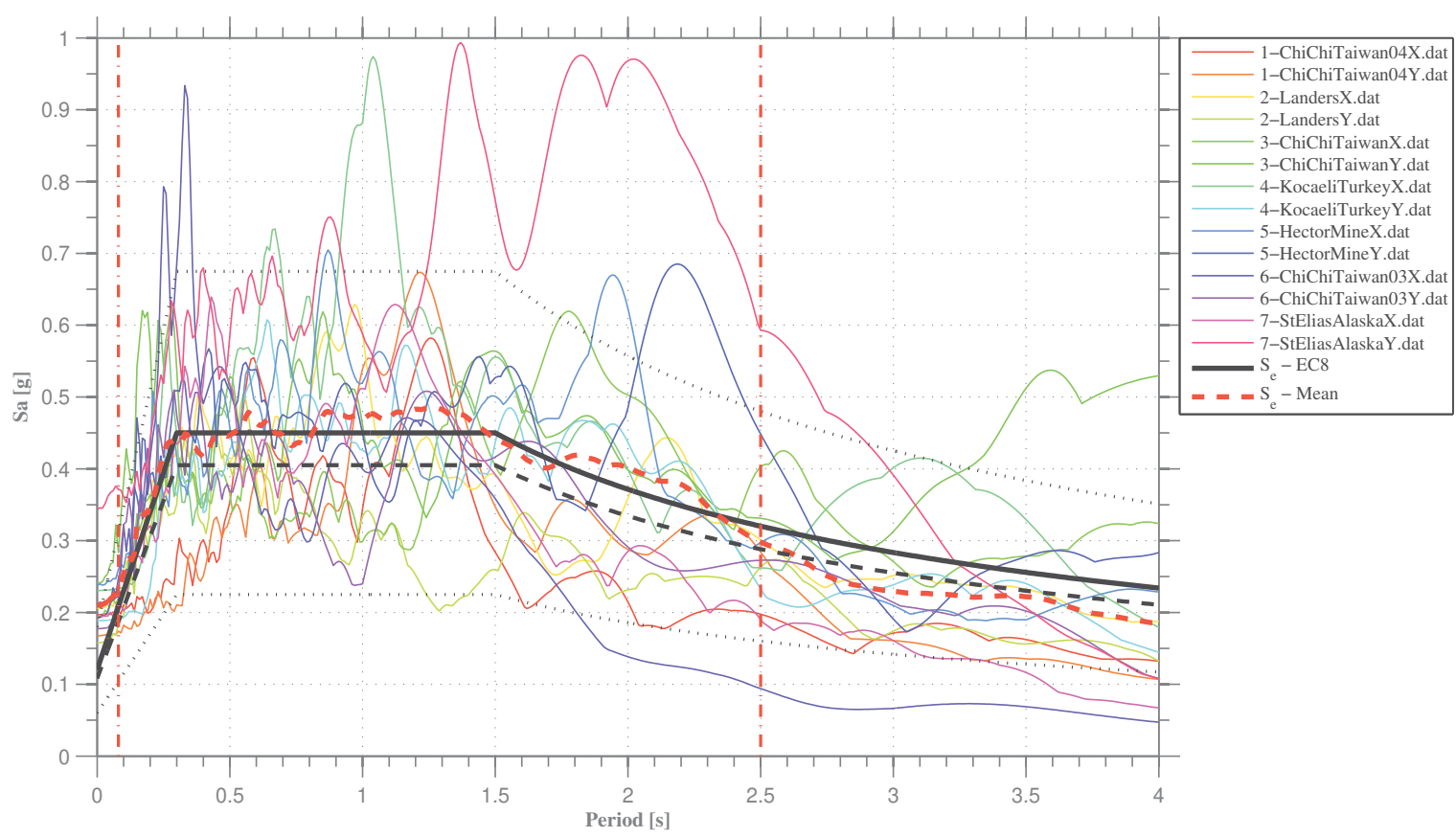

Figure 11: Individual response spectra for each seismic record, average spectrum obtained from seismic records and target spectrum ${ }^{[3]}$

\subsection{Seismic analyses results}

\subsubsection{Longitudinal direction}

As mentioned previously, the supports at the abutments allow the deck to move relatively to the piles in the longitudinal direction meaning that, the frames created by the piers and the crosshead beams absorb the totality of the seismic load applied in this direction. For this reason, in this direction, the top of the pier that deflects the most has been selected as the control node used to create the curves which characterise the behaviour of the structure under the pushover and time-history analysis. In figure 12 are presented the results from both these analyses, as well as the base shear predicted in the spectral analysis.

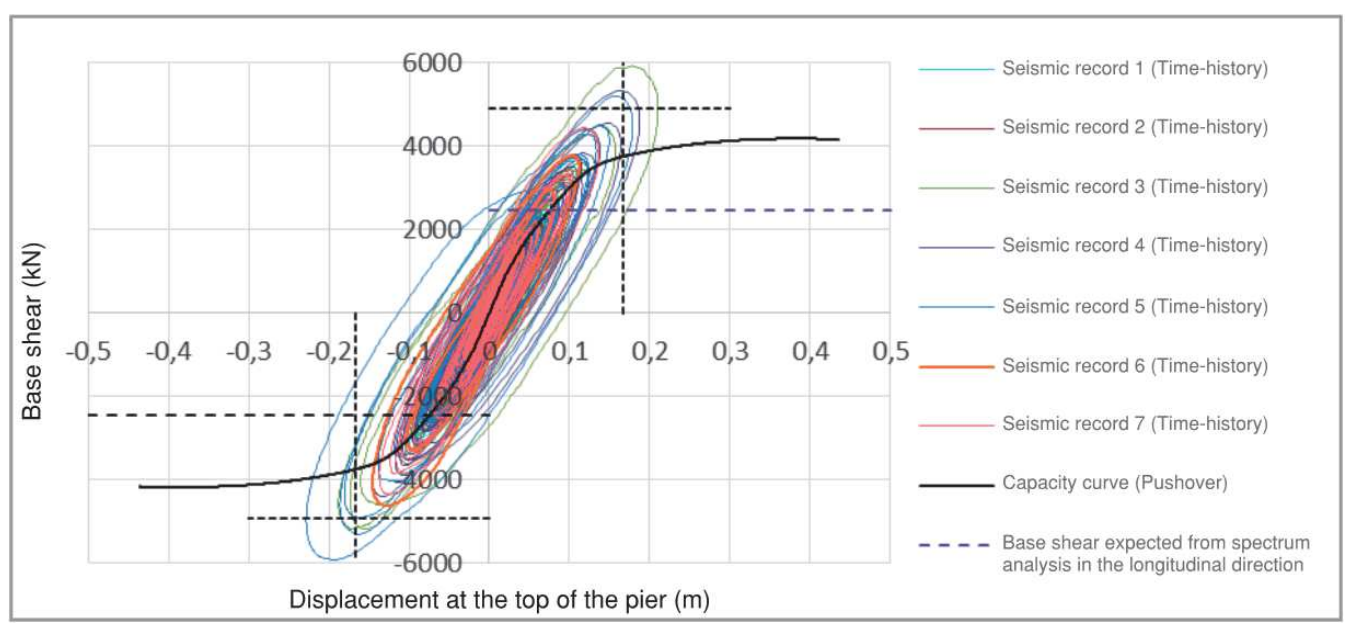

Figure 12: Overlay of load-displacement curves obtained from pushover and time-history analyses and base shear expected from spectral analysis in the longitudinal direction 
Knowing the initial stiffness of the structure in the longitudinal direction and comparing, for each seismic action, the base shear obtained in non-linear regime with the shear base that would have been obtained in a linear regime for the same displacements, it was possible to obtain a behaviour factor for each one of the individual seismic records, as shown in table 2 . Averaging the seven values obtained, we determine the real behaviour favour of the structure in this direction, which is 1.32 .

\begin{tabular}{ccccc}
\hline $\begin{array}{c}\text { Seismic } \\
\text { record }\end{array}$ & $\begin{array}{c}\text { Maximum Load } \\
\mathrm{F}_{\mathrm{NL}}(\mathrm{kN})\end{array}$ & $\begin{array}{c}\text { Displacement } \\
(\mathrm{m})\end{array}$ & $\begin{array}{c}\text { Load in elastic linear regime } \\
\mathrm{F}_{\mathrm{L}}(\mathrm{kN})\end{array}$ & $\begin{array}{c}\text { Behaviour factor } \\
\mathrm{q}\end{array}$ \\
\hline 1 & 3863,52 & 0,108 & 4897,84 & 1,27 \\
\hline 2 & 4287,86 & 0,125 & 5668,80 & 1,32 \\
\hline 3 & 5933,85 & 0,177 & 8027,02 & 1,35 \\
\hline 4 & 5338,79 & 0,162 & 7346,76 & 1,38 \\
\hline 5 & 5931,66 & 0,192 & 8707,27 & 1,47 \\
\hline 6 & 4631,57 & 0,128 & 5804,85 & 1,25 \\
\hline 7 & 4444,13 & 0,119 & 5396,70 & 1,21 \\
\hline & & & & $\mathrm{q}_{\text {médio }}=1,32$ \\
\hline
\end{tabular}

Table 2: Real behavior factor obtained for each seismic record and final behavior factor in the longitudinal direction

\subsubsection{Transversal direction}

\subsubsection{Response on the piers}

It has been first analysed how the seismic action affects the piers of the viaduct in this direction and the results are given similarly to what has been presented in section 4.2.1 - the curves shown below characterise the interaction of the total base shear directed to the piers with the displacement of the control node which is, again, the top of the pier which shows more deflection, for each of the seismic analysis.

Figure 13 shows the overlay of the time-history curves obtained for the seven seismic records, the capacity curve obtained from the pushover analysis and the expected base shear as per spectral analysis.

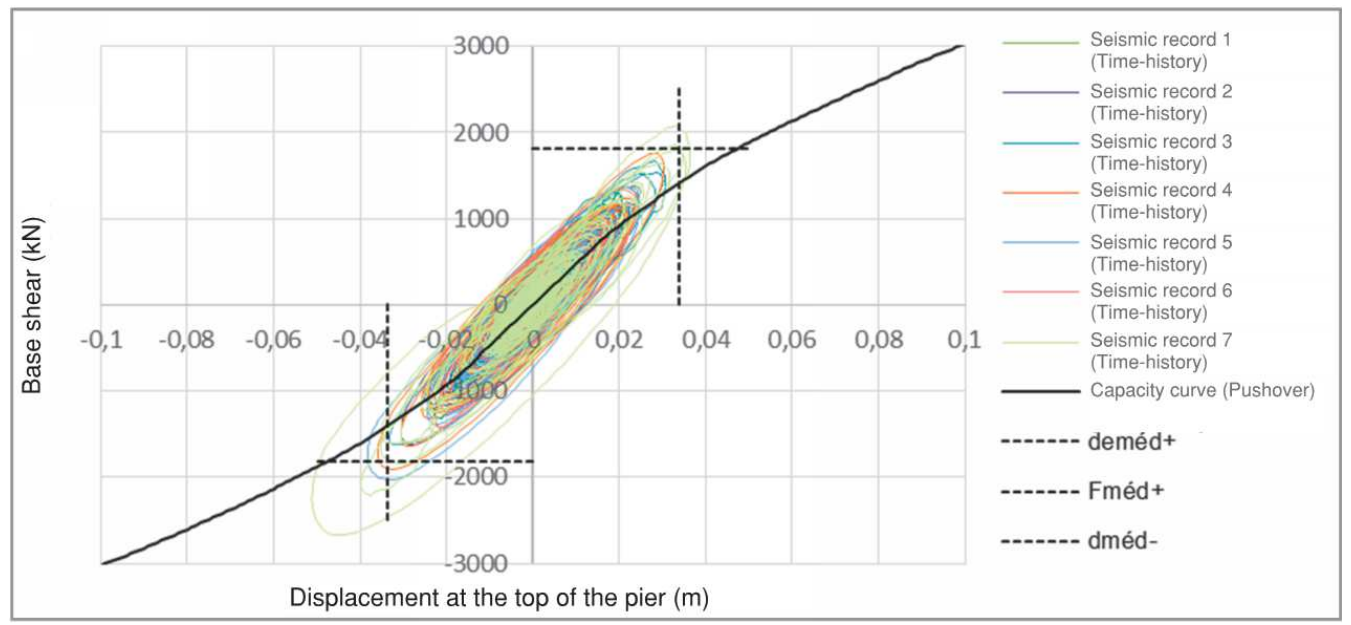


Figure 13: Overlay of load-displacement curves obtained from pushover and time-history analyses in the transversal direction

\subsubsection{Response on the abutment piles}

As previously stated, the piles in the abutments take most of the seismic load applied to the viaduct in the transversal direction due to its increased capacity of dissipating energy which derives from the ground damping.

Figure 14 shows the overlay of the seven response curves created by the time-history analysis, the pushover capacity curve and, lastly, the base shear anticipated at the spectral analysis.

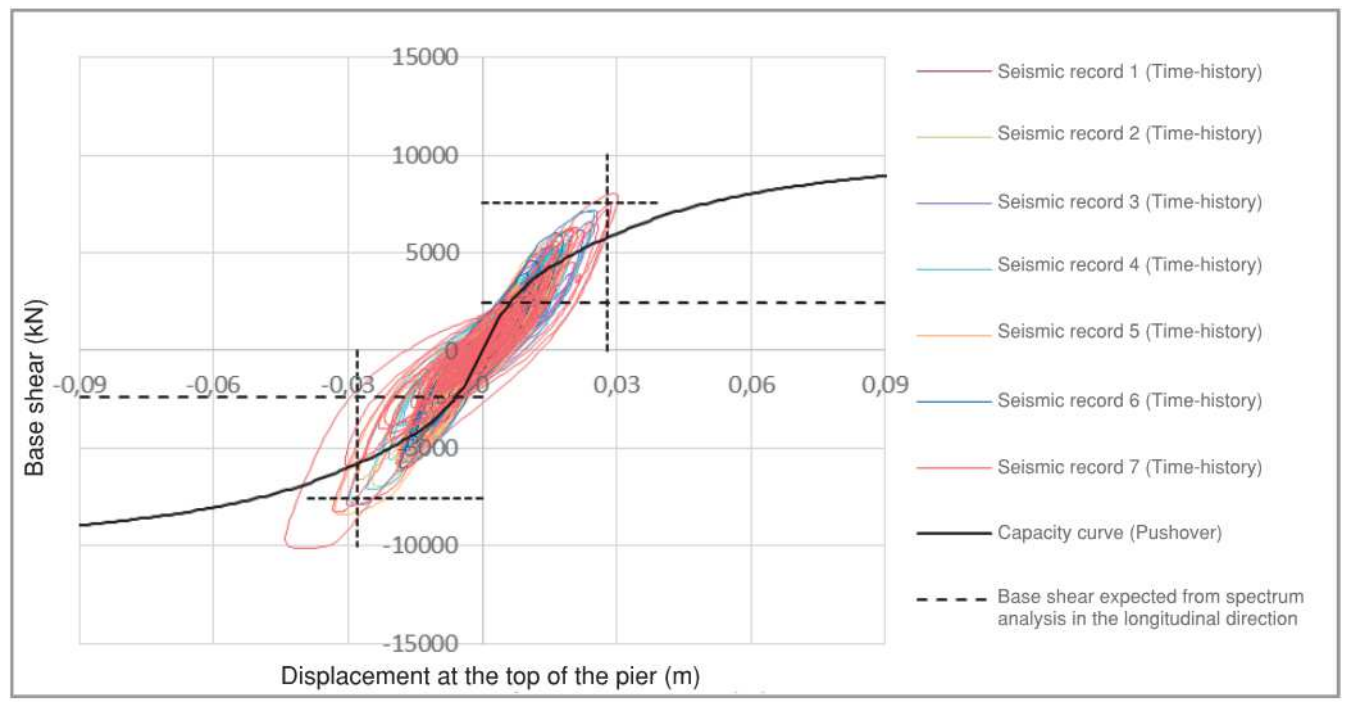

Figure 14: Overlay of load-displacement curves obtained from pushover and time-history analyses and base shear expected from spectral analysis in the transversal direction

Through the same method previously presented to determine the behaviour factor of the structure, in table 3 are listed the Q values calculated for each of the seven seismic loads in the transversal direction and its average.

\begin{tabular}{ccccc}
$\begin{array}{c}\text { Seismic } \\
\text { Record }\end{array}$ & $\begin{array}{c}\text { Maximum Load } \\
\mathrm{F}_{\mathrm{NL}}(\mathrm{kN})\end{array}$ & $\begin{array}{c}\text { Displacement } \\
(\mathrm{m})\end{array}$ & $\begin{array}{c}\text { Load in elastic linear regime } \\
\mathrm{F}_{\mathrm{L}}(\mathrm{kN})\end{array}$ & $\begin{array}{c}\text { Behavior factor } \\
\mathrm{q}\end{array}$ \\
\hline 1 & 6146,35 & 0,0197 & 10014,24 & 1,63 \\
\hline 2 & 6972,77 & 0,0234 & 11895,09 & 1,71 \\
\hline 3 & 7140,08 & 0,0252 & 12810,10 & 1,79 \\
\hline 4 & 7887,49 & 0,0275 & 13979,27 & 1,77 \\
\hline 5 & 8419,13 & 0,0316 & 16063,46 & 1,91 \\
\hline 6 & 6038,76 & 0,0182 & 9251,74 & 1,53 \\
\hline 7 & 10152,12 & 0,0397 & 20180,99 & 1,99 \\
\hline & & & & qmédio $=1,76$
\end{tabular}

Table 3: Real behavior factor obtained for each seismic record and final behavior factor in the transversal direction 
Comparing the Q values obtained in both directions we can observe a higher ductile capacity in the transverse direction, which was predictable considering that, in the orthogonal direction, the soil is not modelled allowing for plastification and, consequently, its response develops in a linear regime.

\subsubsection{Summary of results}

Figure 15 presents a summary of the base shear, bending moment and displacements obtained for each direction through the different analysis. Note that the displacements concerning the pushover analysis are the displacements obtained for the software's convergence limit, that is to say, for the deformation capacity of the structure.

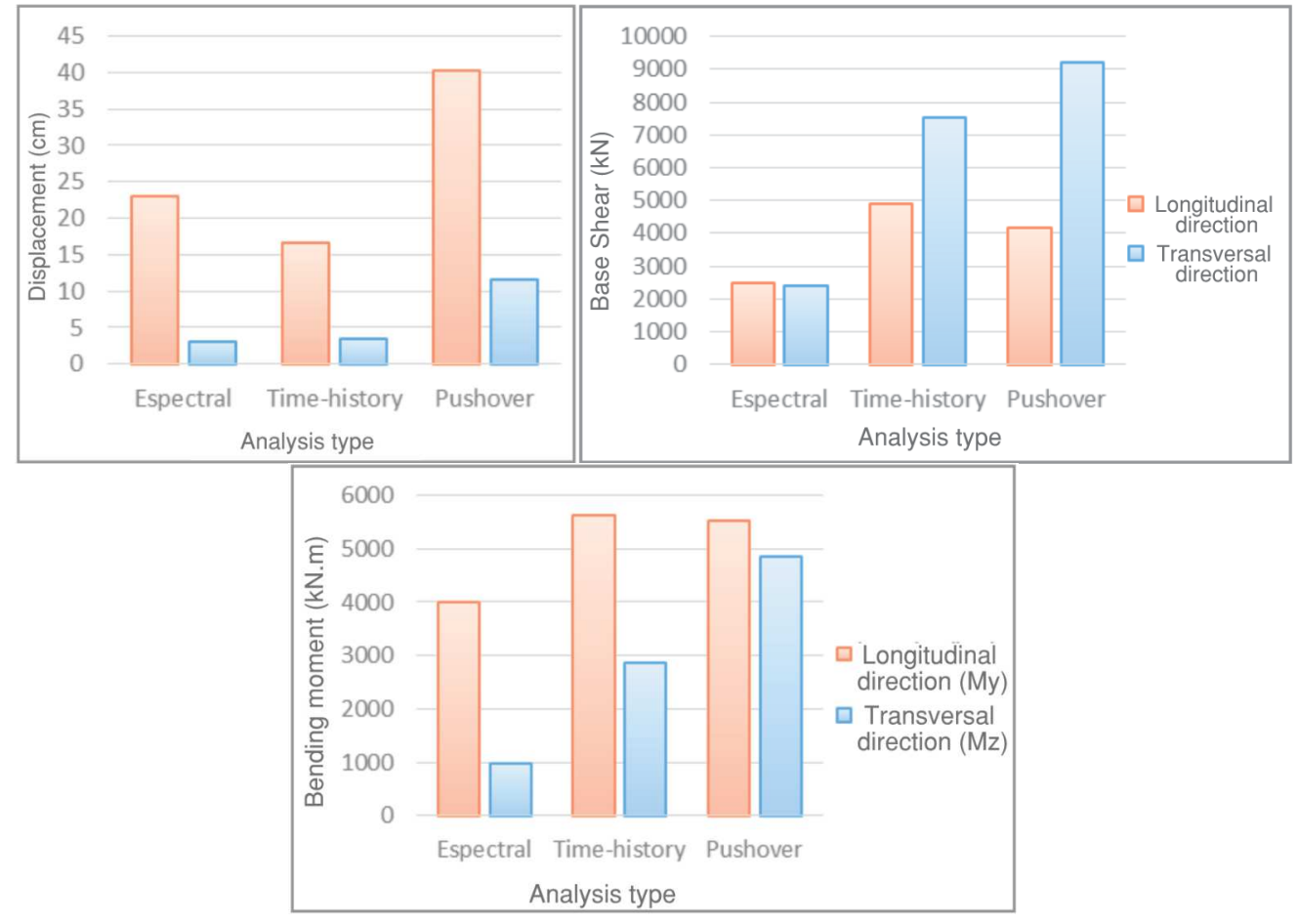

Figure 15: Results in terms of displacement, base shear and bending moment obtained from the different analyses carried out

Comparing the results from all three analysis carried out we can observe that there are significant differences between them. However, this divergence is not indicative of any safety or performance faults and the reasons for such discrepancy can be divided into two groups:

The first group comprises all factors inherent to the calculation. First of all, the approach through the elastic response spectrum assumes the seismic action acting fully in one main direction and only $30 \%$ of the same seismic action applied to the orthogonal direction. On the other hand, the accelerograms used for the non-linear dynamic analysis are pairs of real records and, therefore, are fully applied in both directions. It is then predictable that values for a certain parameter vary when obtained through each of these methods. Secondly, note that, when carrying out the linear dynamic analysis, a behaviour factor is adopted to account for structural system's capacity of dissipating energy and that behaviour factor equally affects all structural elements and nodes, including the ground. However, when carrying out non-linear analysis, it has been assumed that the ground was only capable of dissipating energy in the surrounding area of the abutment piles. Accordingly, the global plasticity of the modelled structure will be lower when performing the latest, originating higher stresses. 
The second group is associated with the non-linearity of the materials. Naturally, taking into account that the non-linearity varies instead of assuming it is kept in its elastic linear state through the analysis and considering a specific non-linearity for each specific element instead of assuming that the all elements are equally ductile, originates results that are more accurate and closer to the real behaviour of the structure once under a real seismic action. The decreasing stiffness not only originates higher displacements, but also changes the fundamental vibration modes of the structural system, altering its response under dynamic actions, a factor that is neither considered in spectral or pushover analysis.

\section{CONCLUSIONS}

Starting by the non-linearity of the soil, the present study has innovated by using multilinear models which include the formation of a gap, significantly decreasing the material damping originated by the ground surrounding the foundations of the viaduct. A simplified study was carried out to evaluate how two specific parameters influence the characteristic hysteretic curve of a particular soil. This study consisted of varying these parameters and observing how each of them affects the global dissipation capacity of a certain structure surrounded by a certain ground type. However, note that the adopted values of the parameters have been based of references describing a silty soil, and the values used here might not be applicable to other types of soils with different deformation characteristics. This is a theme which lacks references and it is considered by the authors of this paper to require further investigation.

Regarding the results from different seismic approaches, it is clear that there are significant discrepancies in the structural response observed when carrying out the two analysis frequently used for seismic design (linear analysis with response spectrum and non-linear dynamic analysis), specifically in the calculation of stresses and deflections. Nonetheless, it can be observed in the results throughout this study that the structure offers a substantial additional capacity compared to what has been estimated in its design stage. We can conclude that, though the results are distinct, the seismic design of structures based on the standardised spectral analysis clearly guarantees safety and good structural performance and that the structure in study is prepared to face a seismic load without compromising the safety of its users or suffering major structural damage. Comparing the structural response observed for the non-linear static analysis with the response recorded with the spectral analysis, it is once more recognised that the structure shows a great extra capacity in both directions of the viaduct. This additional capacity is not as noticeable when measuring the results collected from the pushover analysis and the non-linear dynamic analysis, which is not however discouraging, as this can be due to the damping considered for the time-history analysis.

Following on the above, it becomes clear how important it is to adopt an accurate behaviour factor when using a simplified approach. As this analysis assumes the structure has a certain capacity of creating plastic hinges and dissipating energy, the determination of an accurate Q value is immensely important as, if the behaviour factor adopted varies excessively from the real one, it can lead to the structure suffering further damage than expected, more remedial costs or non-economic designs. For the viaduct in study, the Q value achieved from more accurate analysis has shown to be lower than the value adopted when first designing the structure. However, as mentioned previously, note that this does not mean the structural safety isn't guaranteed as the structure offers a great additional capacity to the load which has been designed for. Hence, if the $\mathrm{Q}$ value adopted had been closer to the real ductility of the structure, a more cost-effective design could have been developed. 


\section{REFERENCES}

[1] Coffer, W. F., Modak, S., Determination of Rheological Parameters of Pile Foundations for Bridges for Earthquake Analysis. Washington State Transportation Center (TRAC), 1997.

[2] Araújo, M., Macedo, L., Marques, M., and Castro, J. M., Code-based record selection methods for seismic performance assessment of buildings. Earthquake Engng Struct. Dyn., 45: 129-148. doi: 10.1002/eqe.2620., 2016

[3] SCT, N-PRY-CAR-6-01-005/01, 2001.

[4] GEG, Dictámen geológico-geotécnico, 2015.

[5] GEG, MD-CPR-T1-PE-EST-PTE1.14 - Memória Descriptiva Proyeto Ejecutivo Puente PTE1.14, 2015.

[6] Arêde, A., Apontamentos da UC DEES, Dinâmica de Estruturas e Engenharia Sísmica, FEUP, 2013.

[7] Chopra, A., Dynamics of Structures, Pearson Education, 2007.

[8] Sivaselvan, M., Reinhorn, A., Hysteretic Models for Deteoriorating Inelastic Structures. Journal of Engineering Mechanics, Julho de 2001.

[9] CEN, EN 1998-2: Eurocode 8: Design of structures for earthquake resistance - Part 2: Bridges, 2005.

[10] CEN, EN 1998-1: Eurocódigo 8: Projeto de Estruturas para Resistência aos Sismos Parte 1: Regras gerais, ações sísmicas e regras para edificios, 2010.

[11] Azevedo, P., Análise de diferentes abordagens para o cálculo sísmico de viadutos no México. Dissertação de Mestrado, Faculdade de Engenharia da Universidade do Porto, 2015. 